\title{
ON THE SPACE-LATTICE OF LIQUID CRYSTALS.
}

\author{
By J. Steph. van der Lingen.
}

\section{INTRODUCTION.}

During the past two years numerous experiments have shown that solid crystals cause interference phenomenon when Röntgen rays are passed through them, and that the positions of maximum interference in the pattern depend upon the direction of transmission of the rays through the crystals, that is, they are dependent on the space-lattices of the crystals.*

Liquid crystals, according to O. Lehmann, only have space-lattices when they are polyhedral in form, similar to solid polyhedral crystals, and when thin layers of the crystalline solution are placed between similar crystalline plates, each of which must have the same orientating effect on the molecules of the solution.

In the second case the structure of the space-lattice is not necessarily the same as in the first case. If these solutions are placed between amorphous plates (glass plates) or dissimilar crystalline plates, then the effect of these plates on the molecules causes the solution to become pseudo-isotropic. In this case only the principal axis of the molecules lies in a fixed direction; the secondary axes lie in all directions.

The principal axis is the axis round which the molecules are most easily rotated. According to $\mathrm{O}$. Lehmann, it is perpendicular to the plane of the molecules, which are in all probability disc-shaped.

When ordinary light is transmitted through such a pseudo-isotropic liquid crystalline layer, then it causes the same optical effects as a uniaxial crystal cut perpendicular to its optic axis.

The question now arises, "Do changes in the molecules themselves cause the different forms of crystals of the same substance, or do aggregations of a different order of the same unchangeable molecules cause the

* W. Friedrich, P. Knipping, and M. Laue, Münch. Sitzber., 1912, p. 303 ; M. Laue and F. Tank, Ann. d. Phys. (4), 41, 1003, 1913 ; W. H. and W. L. Bragg, Proc. Cambridge Phil. Soc., 17, 43, 1913 ; T. Terada, Tôkyô Math. Phys. Soc., 7, 60, 1913. 
different forms?" Are chemical and physical properties dependent on the aggregation of molecules in a substance, or are they dependent upon a change in the structure of the molecule itself?

The conceptions of O. Lehmann, which he explained fully in numerous works, ${ }^{*}$ are in direct contradiction to the theory that molecules do not change their structures whether the substance be gaseous, solid, anisotropic, or amorphous, so much so that W. Nernst denies the existence of liquid crystals. $\dagger$

This theory of the "identity" of molecules, which is based on Avogadro's law, is forced to accept that any change in the space-lattice of a crystal must cause a change in the properties of the crystal such as melting-point, solubility, and vapour pressure. As these changes are not brought about by a plastic deformation of crystals it must be accepted, on this theory, that no change has taken place in the space-lattice of the crystals whether they are solid or liquid crystals. + Consequently the pseudo-isotropic structures of liquid crystals cannot exist.

The pseudo-isotropic layers, which are obtained when the solutions are placed between glass plates, and which may be retained by the influence of a magnetic field, $\S$ when no other force affects the molecules, must have a space-lattice.

D. Vorländer believed that this had been definitely proved by his experiments when he had examined such layers in convergent light. $\mathrm{H}_{\mathrm{i}}$ results, however, are also in accordance with Lehmann's theory of liquid crystals.

The object of my experiments was to determine whether these pseudoisotropic solutions of crystalline substances have a space-lattice or not. If there be a space-lattice then they must cause interference phenomenon when Röntgen rays are passed through them.

In order to find such an effect substances whose molecules could be influenced by a magnetic field were used.

In this case, according to Lehmann, only the principal axis of the molecules has a fixed direction, viz. parallel to the lines of force, and the subordinate axes may lie in any direction, hence the theory of Röntgenray interference phenomenon cannot predict any definite pattern, except that the points on the pattern must trace out symmetrical conic sections. This will be the case if there is a space-lattice, according to Vorländer.

* See O. Lehmann, Die neue Welt der flüssigen Kristalle, Leipzig, 1911. For a full list see “Verzeichuis sämtlicher Veröffentlichungen var Dr. Otto Lehmann," Fr. Vieweg und Sohn, Braunschweig.

$\dagger$ W. Nernst, Theoretischen Chemie, 7th Edition, 1913, p. 666.

† Compare G. Tammann, Zeitsch. f. Electrochem., 1912, p. 587.

$\S$ O. Lehmann, Phys. Zeitsch., 13, 550, 1912.

|| D. Vorländer, Zeitsch. f. phys. Chem., 61, 166, 1907 ; D. Vorländer and H. Hanswaldt, Acta nova, Halle, 90, 1909. 


\section{The Apparatus.}

In order to heat the substance to a fixed temperature a pair of copper spirals were constructed out of two copper cylinders and four copper cylinders.

As these substances had to be placed in a magnetic field equal lengths of copper wire were wound round the coils, so that the current passed in opposite directions round them. This avoided the turning moment of the magnetic field on the spirals (Fig. 1).

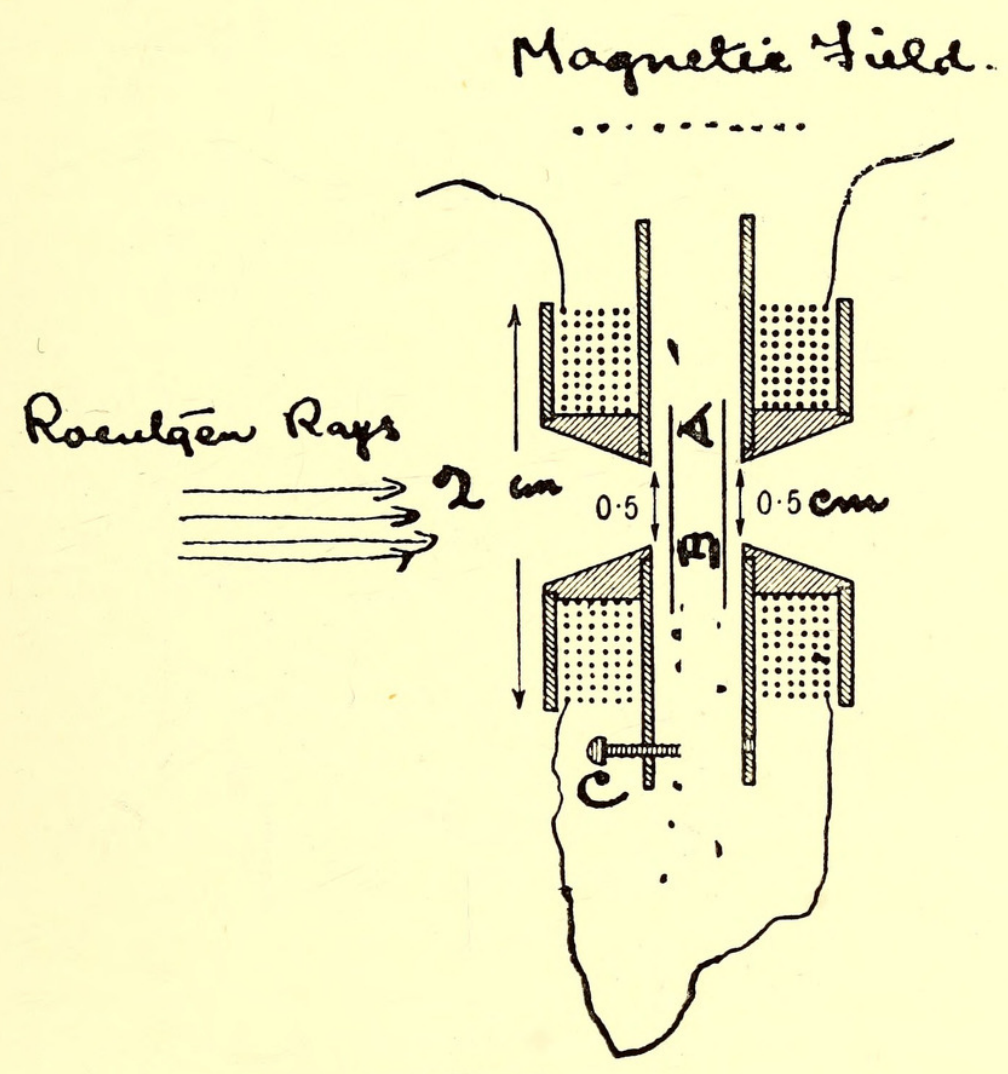

FIG. 1.

BA. The layer of liquid crystals between the glass plates. $\frac{1}{2} \mathrm{~mm}$. thick.

C. Clamping screw.

Between these spirals the substance experimented on is enclosed between two thin glass plates, which are kept in position by means of three screws which clamp the spirals together.

The temperature of the substance between the glass plates was determined by means of a sensitive thermocouple, whose junction just touched the glass plates.

The object of the thermocouple is more to keep the temperature constant than to measure its actual value. 
In order to pass a beam of Röntgen rays through this layer of crystalline solution a cylinder similar to that used by Friedrich and Knipping was used. The openings in the diaphragms were 5 and $3 \mathrm{~cm}$. respectively. This cylinder was placed in front of the crystalline solution, and two photographic films (at a distance of $3.5 \mathrm{~cm}$.) behind it. This is to avoid "faults" and spots of the films in case they are not perfect.

The spirals were clamped between the pole pieces of a Max Kohl electromagnet, after some wadding had been glued on the conical pole pieces in order to avoid heating them.

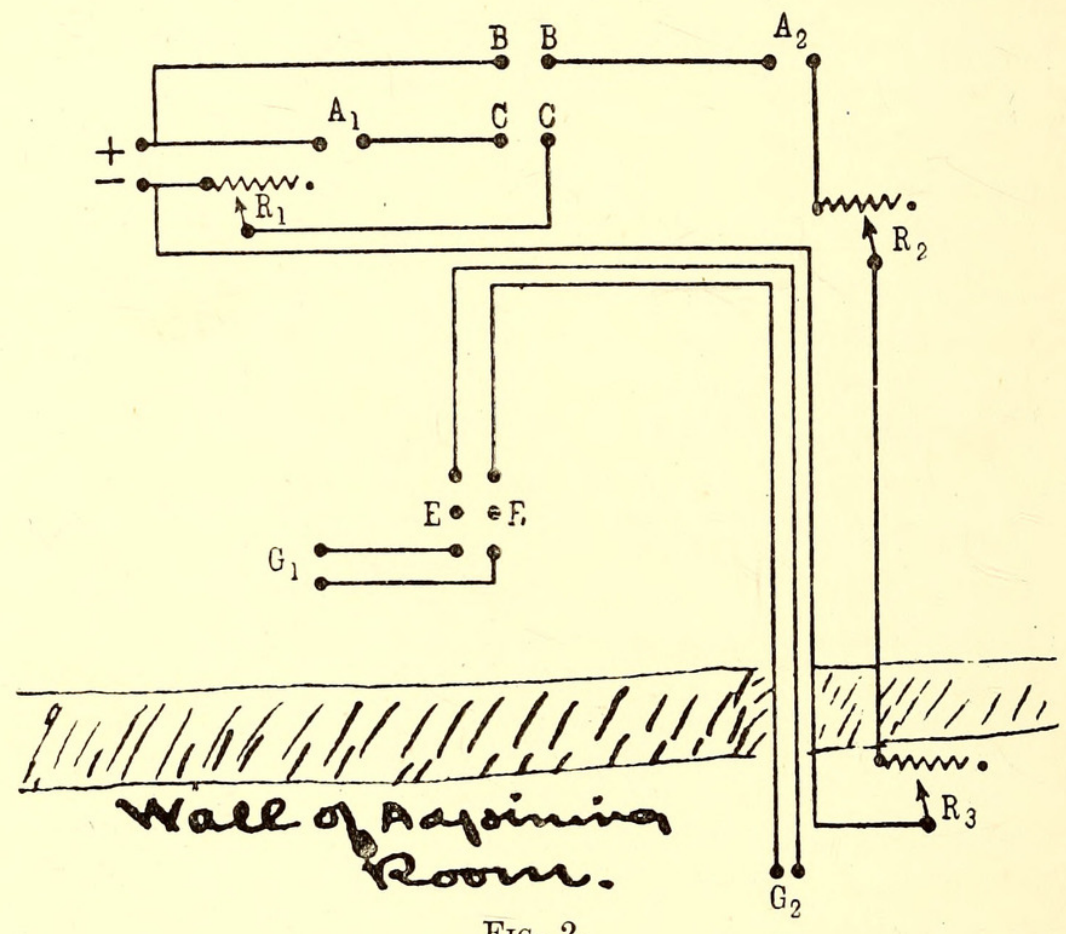

FIG. 2.
$\mathrm{A}_{\mathrm{I}}$ and $\mathrm{A}_{2}$. Ampmeters.
$\mathrm{G}_{\mathrm{I}}$ and $\mathrm{G}_{2}$. Galvanometers.
$R_{1}, R_{2}$, and $R_{3}$. Variable resistances.
BB. Terminals of heating coils.
CC. Terminals of electromagnets.
EE. Terminals of thermocouple.

A good microscope with Nicols was fixed on to a brass holder, which rested on the coils of the electromagnet.

When the microscope with its holder is placed over the magnet, then the pole pieces were between the objective and the object table; thus the solution between the spirals could be examined without any trouble.

During the time of exposure the microscope is removed and the whole of the apparatus covered in between sheets of lead so that only radiations which had passed through the solution could reach the films. 
The electrical connections were according to Fig. 2. The galvanometer $G_{2}$ and resistance $R_{3}$ were placed in an adjoining room in order to protect the experimenter from the rays, and yet enable him to regulate the temperature of the solution.

\section{Method of Experiment.}

The field strengths of the electromagnets, when the spirals are between the poles, was determined by means of a standard Bismuth spiral. These were recorded for various readings of $A_{I}$.

Next the deflections of $G_{1}$ and $G_{2}$ were recorded for various temperatures after the thermocouple had been standardized.

A rubber ring of $1 \mathrm{~cm}$. diameter was cut at a point and then placed on a clean glass plate-object; cover slides $0.17 \mathrm{~mm}$. thick and $18 \mathrm{~mm}$. square were used. A small quantity of the substance is then carefully powdered and placed inside the ring, and covered with a similar glass plate. The whole is then carefully placed between the spirals so that the cut in the ring is uppermost. The junction of the thermocouple is then placed in position. The spirals are then placed between the pole pieces of the electromagnet and clamped in position. The microscope is focused on the substance. The substance is then heated by passing a current through the coils of the spiral. On melting air-bubbles are expelled through the opening in the rubber ring by gently screwing and unscrewing the spirals.

Observations on a layer of $\frac{1}{2} \mathrm{~mm}$. thick of Paraazoxyanisol gave the following results :-

This substance, which was not chemically pure, became amorphous at $124^{\circ}$. The magnetic field has no visible influence on it. At $122^{\circ}$ crystalline drops commence to appear. These flow together, and soon fill the whole field of vision with a crystalline solution. When the magnetic field is put on the axes of these spherical liquid crystals all turn in one direction, so that they become parallel to a fixed direction. The crystalline solution, when the magnetic field is off, appears like a network of dark stripes which move about. When the magnetic field is put on they disappear rapidly. The solution then appears to have the same effects optically as a crystal cut perpendicular to its axis. This can be seen by means of the Nicols which are in front of and behind this crystalline layer.

At $118^{\circ}$ the stripes become broader and shaded at their sides; these vanish rapidly when a field of 3,000 Gauss is put on.

At $104^{\circ}$ the stripes only disappear slowly in a field of 5,000 Gauss.

At $92^{\circ}$ the substance begins to solidify. The magnetic then has only a partial effect on the substance. It appears as if the crystals are then plastic. The edges only show a slight change in colour when a strong magnetic field is put on. 
At $90^{\circ}$ the substance is solidified: the magnetic field has no influence on it. These observations were made during the gradual cooling of the substance.

Similar observations were made on the rotation of the axis of spherical crystals and crystalline solutions of Paraazoxyphenetol with a trace of olive oil ; on Anisaldazin with olive oil and piperin; and also on Paraazoxyanisol with olive oil. The results agree with those obtained by O. Lehmann.*

\section{Röntgen Rays and Liquid Crystals.}

Paraazoxyanisol was heated until it became amorphous. It was then allowed to cool gradually in a magnetic field of 5,000 Gauss.

The object of this was to see whether the principal axes remained parallel to the magnetic field, or whether they changed during the process of solidification. If they remain fixed then the interference pattern must show radial lines on the films.

After an exposure of four hours one film was removed and developed. It clearly showed interference phenomenon but no symmetry at all. The pattern obtained is similar to those of Hupka $\dagger$ in his experiments on microcrystalline substances.

The second film was developed after an exposure of eight hours, and also showed the same unsymmetrical interference points on the film.

From these results we conclude that the axes did not remain fixed when the substance was allowed to solidify in this magnetic field. This could also be seen on microscopic examination of the layers.

Secondly, we see that such layers do cause interference phenomenon which is not absorbed by the glass plates.

The same layer was then heated up to $118^{\circ}$ in a magnetic field of 5,000 Gauss, and carefully observed for half an hour by means of the microscope. The temperature was kept constant by observing the deflection of $G_{1}$, which was kept constant by regulating the current through the spirals by means of $R_{2}$.

As no change was observed the microscope was removed, the cylinder with diaphragms placed in front of the solution, two films behind the solution, and the whole covered in with lead sheets. $G_{2}$ was switched and the temperature regulated by $R_{3}$.

After an exposure of eight hours the first film was developed. It showed no trace of interference phenomenon. Only dispersion of the rays could be observed, viz. an enlargement of the central spot which is due to direct transmission of the rays.

* O. Lehmann, Phys. Zeitsch., 13, 550, 1912.

† E. Hupka, Phys. Zeitsch., 14, 623, 1913, fig. 3. 
The second film was developed after an exposure of sixteen hours. It also showed no trace of interference phenomenon. Only an increase in the dispersion-which is probably not due to the solution-could be observed.

In an experiment with Paraazoxyphenetol and a trace of olive oil no interference pattern was obtained after an exposure of twenty hours. On examining the solution microscopically the oil could be seen collected in small globules on the glass plates. On switching the magnetic field off the stripes reappeared between these globules.

These experiments show that crystalline solutions of Paraazoxyanisol and Paraazoxyphenetol with olive oil have no space-lattice.

In connection with this work I wish to express my sincere thanks to Professor Max von Laue, Institut international de physique Solvay, and to the Kgl. Preussischen Akademie der Wissenschaften for their aid in carrying out this work. 


\section{$2 \mathrm{BHL}$ Biodiversity Heritage Library}

Lingen, J. Steph. van der. 1915. "ON THE SPACE-LATTICE OF LIQUID

CRYSTALS." Transactions of the Royal Society of South Africa 5, 45-51. https://doi.org/10.1080/00359191509519714.

View This Item Online: https://www.biodiversitylibrary.org/item/181589

DOI: https://doi.org/10.1080/00359191509519714

Permalink: https://www.biodiversitylibrary.org/partpdf/175545

\section{Holding Institution}

Smithsonian Libraries

\section{Sponsored by}

Biodiversity Heritage Library

\section{Copyright \& Reuse}

Copyright Status: Not in copyright. The BHL knows of no copyright restrictions on this item.

This document was created from content at the Biodiversity Heritage Library, the world's largest open access digital library for biodiversity literature and archives. Visit BHL at https://www.biodiversitylibrary.org. 